\title{
Food intake and prevalence of obesity in Brazil: an ecological analysis
}

\author{
Jackeline Christiane Pinto Lobato ${ }^{1, *}$, Antonio José Leal Costa ${ }^{1}$ and Rosely Sichieri ${ }^{2}$ \\ ${ }^{1}$ Institute of Public Health, Federal University of Rio de Janeiro, Rua Marechal Bittencourt 57/1003, Riachuelo, \\ Rio de Janeiro - RJ, CEP 20950-200, Brazil: ${ }^{2}$ Institute of Social Medicine, State University of Rio de Janeiro, \\ Rio de Janeiro, Brazil
}

Submitted 2 March 2008: Accepted 25 February 2009: First published online 20 April 2009

\begin{abstract}
Objective: To investigate the correlation between the consumption of refined carbohydrates and fats and the prevalence of obesity in the state capitals of Brazil. Design: An ecological evaluation of obesity and dietary risk factors was carried out in twenty-six state capitals of Brazil.

Setting: Analysis was based on the age-standardized prevalence of obesity (BMI $\geq 30 \cdot 0 \mathrm{~kg} / \mathrm{m}^{2}$ ) among adults aged $20-59$ years. Both intake and obesity prevalence were obtained from the last National Family Household Budget Survey (HBS). The survey was conducted from July 2002 to June 2003, based on a probabilistic national sample of 48470 households. In each household, during seven consecutive days, all monetary and non-monetary expenses for food and beverages for family consumption were transformed into energy. The relative contribution of foods and food groups was expressed as the proportion (\%) of total energy. Fruits and vegetables were also measured by the quantity bought in grams.

Results: Prevalence of obesity varied from $5 \cdot 1 \%$ to $13 \cdot 6 \%$ among women and from $5 \cdot 2 \%$ to $17 \cdot 6 \%$ among men. For women, there were statistically significant correlations between obesity and intake of sugar and soft drinks $\left(r_{\mathrm{S}}=0 \cdot 60\right.$; $P=0.001)$, ready-to-eat meals $\left(r_{\mathrm{S}}=0.39 ; P=0.05\right)$ and potatoes $\left(r_{\mathrm{S}}=0.40\right.$; $P=0 \cdot 04)$. For men there were no such associations.

Conclusions: Increasing intake of refined carbohydrates, mainly soft drinks, may play a role in the prevalence of obesity among women in Brazil. Effecting changes in family purchase patterns may be a strategy to reduce obesity.
\end{abstract}

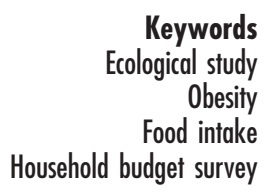

Keywords

Obesity

Food intake

Household budget survey
The whole world is experiencing an obesity epidemic, affecting individuals of all ages, in all social strata and ethnic groups ${ }^{(1,2)}$. Although obesity is related to genetic, metabolic, behavioural and environmental influences, its rapid increase suggests that behavioural and environmental influences, rather than biological changes, are the major underlying cause ${ }^{(1-3)}$.

There has been a marked shift recently in the composition of the diet, with an increase in per capita energy availability, higher consumption of soft drinks and larger portion sizes $^{(2)}$, as well as higher intakes of fat and added sugar, accompanied by a dramatic fall in total cereal and fibre intakes ${ }^{(1,4)}$.

Rice and beans used to be the staple foods in Brazil, but recent data show a decrease in their intake, whereas there has been a $400 \%$ increase in the consumption of industrialized products such as soft drinks ${ }^{(5)}$. Trends between 1974 and 2003 in Brazil also indicated high consumption of sugar, total fat and saturated fat, and insufficient intakes of vegetables and fruits ${ }^{(5)}$. During the same period, the prevalence of obesity in Brazil rose from
$2 \cdot 8 \%$ to $8 \cdot 8 \%$ among adult men, and from $7 \cdot 8 \%$ to $12 \cdot 7 \%$ among women ${ }^{(6)}$.

Ecological studies in the USA have found a strong positive association between the intake of refined carbohydrates in the form of corn syrup and the prevalence of type 2 diabetes and obesity, and a negative association with dietary fibre intake ${ }^{(7)}$. Data from twenty countries found a positive association between the prevalence of overweight and obesity and the proportion of energy from fat ${ }^{(8)}$.

Our aim in the present study was to investigate the correlation between consumption of refined carbohydrates and fats and obesity prevalence among adults in the state capitals of Brazil.

\section{Methodology}

An ecological study was conducted, using as units of analysis the adult population living in twenty-six state capitals of Brazil in 2003. Data were obtained from the 2002-3 National Family Household Budget Survey (HBS; 
'Pesquisa de Orçamentos Familiares'), conducted by the Brazilian Institute for Geography and Statistics from July 2002 to June 2003 on a probabilistic national sample of 48470 households, throughout the year. A two-stage cluster sampling with stratification by urban and rural areas of the states, as well as stratification by the average household schooling, was employed. The primary sampling units were selected by systematic sampling proportional to the number of households. Households were selected by simple random sampling. The household interviews were distributed over the twelve months of the year. The sample was designed to provide representative estimates at the national, regional and state and capital levels ${ }^{(5)}$.

The HBS obtained information about the family food purchases for each household during seven consecutive days. All monetary and non-monetary expenses for food and beverage consumption were registered, including each product acquired, amounts and portion sizes. The short period of reference - one week of data collection only allows for estimations of groups of families. Crude weights of purchased foods were transformed into energy and nutrients with the use of Brazilian ${ }^{(9,10)}$ and international $^{(11)}$ food composition tables.

The relative contribution of foods and food groups was expressed as the proportion (\%) of total energy. Fruits and vegetables were also analysed in grams, assuming that weekly family purchase was a good estimation for these foods. Other items such as beans and rice are usually bought on a monthly basis. There were initially 820000 foods and beverages in the data set which were grouped into 214 food items based on the frequency of purchase and the major constituents of the foods. These food items were further combined into fifteen groups including three groups of staple foods: (i) cereals and cereal products; (ii) beans, soya, lentils and garbanzo beans; (iii) roots; (iv) milk and milk products; (v) eggs; (vi) meat and meat products; (vii) fruits and natural fruit juices; (viii) vegetables; (ix) sugar and soft drinks; (x) butter and animal fats; (xi) oils and margarine; (xii) alcoholic beverages; (xiii) ready-to-eat meals including lasagne, pizza, soups, frozen rice and chicken, meat and vegetables, and other industrialized frozen dishes; (xiv) oleaginous seeds; and (xv) condiments. For analysis, we excluded the eggs, oleaginous seeds and condiments groups as they had a low frequency of family purchase. Our grouping is quite similar to the Data Food Networking (DAFNE) food classification system used in Europe ${ }^{(12)}$.

Prevalence of obesity was estimated as the proportion of the population with $\mathrm{BMI} \geq 30 \cdot 0 \mathrm{~kg} / \mathrm{m}^{2}$. Height and weight were measured in the households. Height was measured to the nearest $0.5 \mathrm{~cm}$ using a wall-mounted stadiometer and body weight was measured using a calibrated digital scale with maximum capacity of $150 \mathrm{~kg}$ and precision of $100 \mathrm{~g}$. Analysis included all individuals aged 20-59 years, excluding pregnant and breast-feeding women.

Extreme values of BMI - below $13.0 \mathrm{~kg} / \mathrm{m}^{2}$ and above $50 \cdot 0 \mathrm{~kg} / \mathrm{m}^{2}$ - were considered to be due to measurement error and were excluded. The gender-specific age-standardized prevalence of obesity was calculated for each state capital, using as standard the 2003 Brazilian adult population. However, Palmas, the capital of a recently created state, was excluded from the analysis owing to its unstable population structure, mainly among males.

Spearman correlation coefficients between foods and food groups and the prevalence of obesity were calculated separately for men and women. Statistical significance was set at the $5 \%$ level $(\alpha=0 \cdot 05)$. All $P$ values obtained were two-sided. All analyses were performed taking into account the complex sample survey design of HBS, using the SPSS statistical software package version $13 \cdot 0$ (SPSS Inc., Chicago, IL, USA).

\section{Results}

The age-standardized prevalence of obesity was $9 \cdot 75 \%$ and $10.77 \%$ among women and men, respectively, ranging from $5 \cdot 11 \%$ to $13 \cdot 61 \%$ among women and from $5 \cdot 22 \%$ to $17 \cdot 57 \%$ among men. The highest prevalence was in Macapá (north region) for men (17.57\%) and in João Pessoa (north-east region) for women (13.61\%). Women were fatter than men in all south-east capitals and in most cities of the other regions (Table 1).

Overall mean daily household energy availability for the twenty-six capitals was $7577 \mathrm{~kJ}$ ( $1811 \mathrm{kcal})$ per capita, with great variability in the relative contribution of foods

Table 1 Age-standardized prevalence of obesity among adults aged 20-59 years, by sex, in Brazil and selected Brazilian state capitals, 2002-3

\begin{tabular}{|c|c|c|c|c|}
\hline Region & Capital & Men & Women & Total \\
\hline \multirow[t]{6}{*}{ North } & Porto Velho & $10 \cdot 94$ & $12 \cdot 47$ & $11 \cdot 70$ \\
\hline & Rio Branco & $9 \cdot 74$ & $7 \cdot 60$ & 8.67 \\
\hline & Manaus & $8 \cdot 82$ & $8 \cdot 73$ & 8.77 \\
\hline & Boa Vista & $13 \cdot 08$ & $12 \cdot 08$ & $12 \cdot 58$ \\
\hline & Belém & $10 \cdot 10$ & $10 \cdot 80$ & $10 \cdot 45$ \\
\hline & Macapá & $17 \cdot 57$ & $9 \cdot 61$ & 13.59 \\
\hline \multirow[t]{9}{*}{ North-east } & São Luiz & $5 \cdot 73$ & $5 \cdot 11$ & $5 \cdot 42$ \\
\hline & Teresina & $8 \cdot 49$ & $9 \cdot 16$ & 8.83 \\
\hline & Fortaleza & $10 \cdot 36$ & $9 \cdot 49$ & 9.93 \\
\hline & Natal & $10 \cdot 16$ & $10 \cdot 48$ & $10 \cdot 32$ \\
\hline & João Pessoa & $12 \cdot 76$ & $13 \cdot 61$ & $13 \cdot 19$ \\
\hline & Recife & $15 \cdot 34$ & $13 \cdot 17$ & $14 \cdot 26$ \\
\hline & Maceió & $7 \cdot 95$ & $11 \cdot 23$ & $9 \cdot 59$ \\
\hline & Aracaju & 8.43 & $7 \cdot 24$ & $7 \cdot 84$ \\
\hline & Salvador & $5 \cdot 22$ & $11 \cdot 68$ & $8 \cdot 45$ \\
\hline \multirow{4}{*}{ South-east } & Belo Horizonte & $5 \cdot 50$ & 11.53 & 8.51 \\
\hline & Vitória & $9 \cdot 85$ & $13 \cdot 41$ & $11 \cdot 63$ \\
\hline & Rio de Janeiro & $10 \cdot 64$ & $11 \cdot 22$ & $10 \cdot 93$ \\
\hline & São Paulo & $10 \cdot 29$ & $10 \cdot 77$ & $10 \cdot 53$ \\
\hline \multirow[t]{3}{*}{ South } & Curitiba & $12 \cdot 72$ & $10 \cdot 86$ & $11 \cdot 79$ \\
\hline & Florianópolis & $6 \cdot 21$ & $5 \cdot 75$ & 5.98 \\
\hline & Porto Alegre & $7 \cdot 60$ & $12 \cdot 09$ & $9 \cdot 15$ \\
\hline \multirow[t]{4}{*}{ Mid-west } & Campo Grande & $8 \cdot 74$ & $8 \cdot 70$ & 8.72 \\
\hline & Cuiabá & $13 \cdot 00$ & $13 \cdot 52$ & $13 \cdot 26$ \\
\hline & Goiânia & $10 \cdot 84$ & $7 \cdot 97$ & $9 \cdot 40$ \\
\hline & Brasília & $12 \cdot 31$ & $7 \cdot 49$ & $9 \cdot 90$ \\
\hline Total & & $9 \cdot 75$ & $10 \cdot 77$ & $10 \cdot 32$ \\
\hline
\end{tabular}




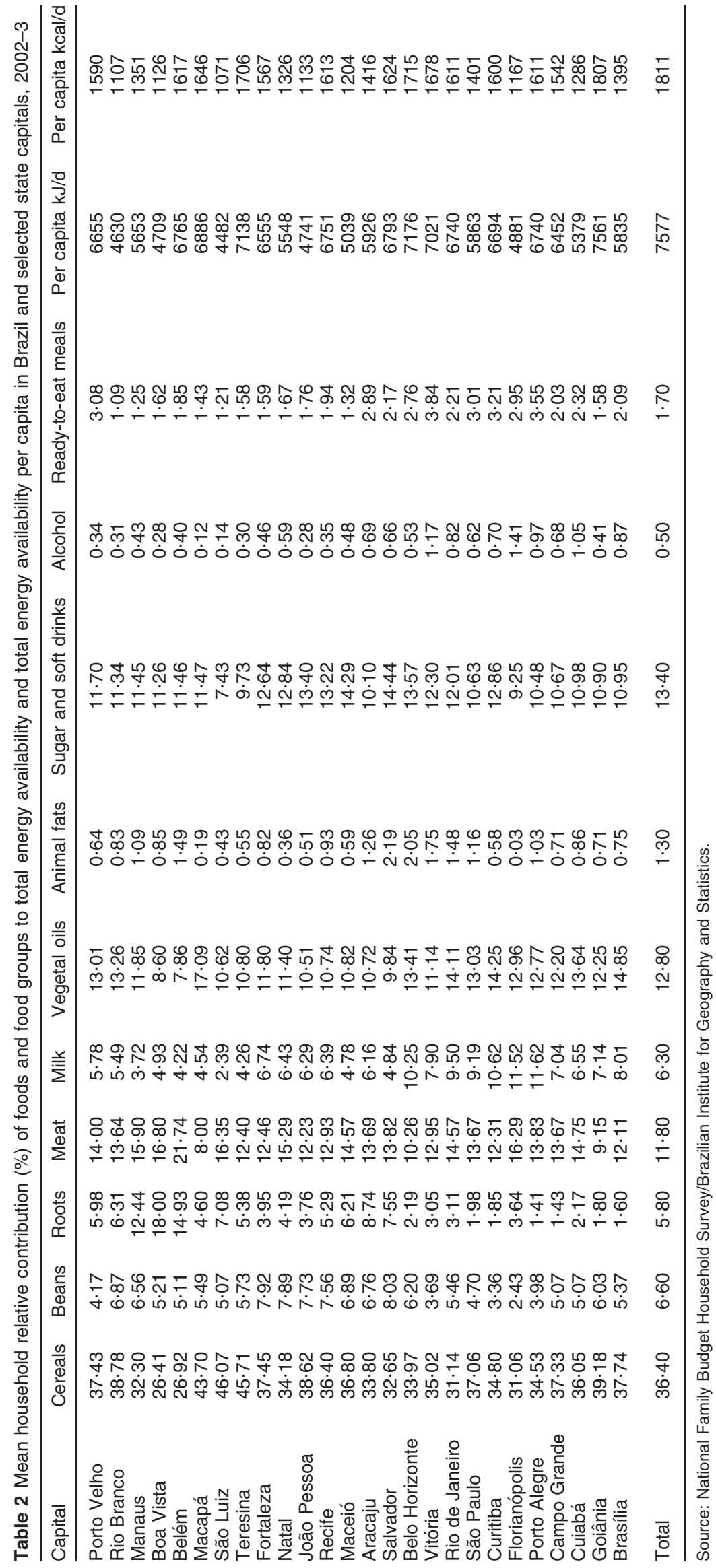


Table 3 Spearman's correlation $\left(r_{\mathrm{s}}\right)$ between the relative contribution of some foods and food groups to total energy intake (\%) and intake in grams for fruits and vegetables and the adult ageadjusted prevalence of obesity in twenty-six state capitals of Brazil, by sex, 2002-3

\begin{tabular}{|c|c|c|c|c|}
\hline \multirow[b]{2}{*}{ Food (\%) } & \multicolumn{2}{|c|}{ Men } & \multicolumn{2}{|c|}{ Women } \\
\hline & $r_{\mathrm{S}}$ & $P$ & $r_{\mathrm{S}}$ & $P$ \\
\hline Cereals & 0.176 & 0.389 & -0.223 & 0.273 \\
\hline Rice & 0.078 & 0.704 & -0.290 & 0.151 \\
\hline Bread & $-0 \cdot 121$ & 0.555 & 0.089 & 0.667 \\
\hline Biscuits & -0.187 & 0.359 & 0.274 & $0 \cdot 175$ \\
\hline Pasta & 0.068 & 0.741 & 0.352 & 0.078 \\
\hline Wheat flour & 0.286 & 0.157 & 0.284 & $0 \cdot 159$ \\
\hline Beans & -0.024 & 0.908 & 0.002 & 0.993 \\
\hline Roots & $-0 \cdot 123$ & 0.550 & -0.077 & 0.709 \\
\hline Potatoes & 0.050 & 0.809 & 0.396 & 0.045 \\
\hline Manioc & 0.198 & 0.332 & $0 \cdot 305$ & $0 \cdot 129$ \\
\hline Meat & -0.262 & 0.195 & -0.014 & 0.944 \\
\hline Milk & 0.031 & 0.879 & 0.121 & 0.557 \\
\hline Fruits $(\mathrm{g})$ & $-0 \cdot 156$ & 0.448 & 0.337 & 0.093 \\
\hline Vegetables (g) & -0.045 & 0.825 & 0.303 & $0 \cdot 132$ \\
\hline Vegetal oils & 0.253 & 0.212 & $-0 \cdot 120$ & 0.559 \\
\hline Soya oil & $0 \cdot 171$ & 0.403 & -0.268 & $0 \cdot 185$ \\
\hline Margarine & 0.122 & 0.552 & 0.357 & 0.073 \\
\hline Animal fats & $-0 \cdot 212$ & 0.298 & 0.322 & $0 \cdot 109$ \\
\hline Butter & -0.271 & $0 \cdot 181$ & 0.263 & $0 \cdot 195$ \\
\hline Sugar and soft drinks & 0.183 & 0.372 & 0.597 & 0.001 \\
\hline Sugar & $0 \cdot 180$ & 0.380 & 0.350 & 0.080 \\
\hline Soft drinks & -0.029 & 0.888 & 0.401 & 0.042 \\
\hline Alcohol & -0.239 & 0.239 & 0.047 & $0 \cdot 820$ \\
\hline Ready-to-eat meals & -0.033 & 0.872 & 0.393 & 0.047 \\
\hline
\end{tabular}

and food groups to the total energy availability (Table 2). For the cereals group the mean ranged from $26 \cdot 41 \%$ to $46.07 \%$; for vegetal oils, from $7 \cdot 86 \%$ to $17 \cdot 09 \%$; for meats, from $8.00 \%$ to $21.74 \%$; and for sugar and soft drinks, from $7 \cdot 43 \%$ to $14 \cdot 44 \%$.

Spearman correlation coefficients between foods and food groups and the prevalence of obesity are shown in Table 3. Among men, neither foods nor food groups were correlated with the prevalence of obesity. Among women, there was a statistically significant positive correlation between the sugar and soft drinks group and the prevalence of obesity (Fig. 1). When sugar and soft drinks were analysed separately, there were weaker correlations of borderline statistical significance, with soft drinks showing a higher correlation with the prevalence of obesity than sugar $\left(r_{\mathrm{S}}=0.401 ; P=0.04\right.$ for soft drinks and $r_{\mathrm{S}}=0.350 ; P=0.08$ for sugar). Ready-to-eat meals, which usually have a high fat content, were also significantly positively correlated with obesity prevalence among women $\left(r_{\mathrm{S}}=0 \cdot 393 ; P=0 \cdot 047\right)$.

There was no correlation between obesity and root foods, although for potatoes this correlation was positive $\left(r_{\mathrm{S}}=0.396 ; P=0 \cdot 04\right)$. No correlation was found for cereals or beans. Pasta showed a fair positive correlation, although with a borderline statistical significance $\left(r_{\mathrm{S}}=\right.$ $0 \cdot 352 ; P=0 \cdot 078)$.

Fruits and vegetables were analysed as percentage of energy contributed to total energy intake and also by the acquired quantity in grams. Although the correlation



Fig. 1 Scatter plot for the association between the relative contribution of sugar and soft drinks to total energy intake (\%) and the age-standardized prevalence of obesity among women aged 20-59 years in twenty-six state capitals of Brazil, 2002-3

was positive $\left(r_{\mathrm{S}}=0.337 ; P=0.093\right)$, there was no significant correlation with the prevalence of obesity.

A secondary analysis was made controlling for socioeconomic status, i.e. average schooling of all adults (20-59 years) and household per capita income. The partial correlations were materially unchanged after this adjustment.

Excluding from the analysis those two cities that appeared to be more influential in the association between soft drinks and obesity, the association was reduced and was still statistically significant $\left(r_{\mathrm{S}}=0 \cdot 481 ; P=0 \cdot 001\right)$.

In order to deal with the many comparisons evaluated, a Bonferroni correction (dividing the significance level (5\%) by the number of correlations (forty-eight) was done. This conservative analysis still showed an association between sugar and soft drinks and the prevalence of obesity in women $\left(r_{\mathrm{S}}=0.597 ; P=0.001\right)$.

\section{Discussion}

There is no clear explanation for the lack of association we found between food group purchase and obesity in men. The prevalence of obesity is increasing within the adult population in Brazil, especially among women; however, men are catching up ${ }^{(6)}$. Women appear to be more susceptible to obesity. Therefore, at the beginning of the obesity epidemic in Brazil, differences by sex were approximately $5 \%$ in 1975, and this difference increased to $8 \%$ in $1989^{(13)}$. From the most recent data reported in the present study, the gap between the sexes is highly reduced (1\%). Studies from the USA also have shown that as the changes increase, the gender difference diminishes or even disappears ${ }^{(13)}$.

That adult men eat out more frequently than women may explain the decreasing gender difference. A study 
conducted in Rio de Janeiro in 1996 showed that 50\% of adult men's meals and snacks were eaten away from home, without utilization of home food ${ }^{(14)}$, whereas the corresponding figure for women was about $20 \%$. Eating out is recognized as a limitation of HBS. HBS data from the USA, in 1995, revealed that $29 \%$ of meals and snacks were consumed away from home ${ }^{(15)}$. As a strategy to overcome this limitation of the data source, we used the relative contribution of food to the total energy intake as our main explanatory variable. However, this cannot account for differences in the composition of meals eaten at home and away from home, and therefore the results for women are probably more reliable than those for men.

Despite these limitations, HBS have been widely used to assess the food availability of populations, allowing between-country comparisons and providing a detailed description of the dietary choices of the population, as well as of population subgroups ${ }^{(1)}$. Also, cross-sectional studies of the association between dietary factors and obesity are highly prone to reverse causality and ecological strategies may be a way of avoiding the under-reporting of eating that occurs in all surveys of food intake, as indicated by studies using doubly labelled water ${ }^{(17)}$.

The main result of the present study is the positive correlation between consumption of sugar and soft drinks and prevalence of obesity among women. These correlations were weaker when analysed separately, with soft drinks, per se, having a higher correlation than sugar.

The mean relative contribution of sugar and soft drinks to total energy intake in all twenty-six Brazilian capitals was $13 \cdot 4 \%$, whereas the WHO/FAO (2003) recommendation $^{(18)}$ is that the consumption of refined sugar must represent a maximum of $10 \%$ of total energy intake. This increased consumption of soft drinks and sugar-sweetened fruit drinks is a critical element in the shift in dietary patterns worldwide ${ }^{(19-21)}$, and our result suggests that populations with a high purchase of soft drinks and sugar have a higher prevalence of obesity.

High consumption of sugar-sweetened drinks was associated with increased energy intake and obesity in children in an observational prospective study in conducted in the $\mathrm{USA}^{(7)}$. Also, soft drink consumption among US children and adolescents displaces milk and fruit juice consumption $^{(20)}$.

Shifts in the availability of sugar, based on FAO data between 1962 and 2000, show an annual increase of $310 \mathrm{~kJ}$ ( $74 \mathrm{kcal})$ per capita per day in the consumption of sugar and a positive correlation of sugar intake with per capita income and proportion of the urban population ${ }^{(22)}$. Sugar consumption has been linked with industrialization and the proliferation of processed food and beverages ${ }^{(21)}$.

Time trends (1974-2003) in metropolitan areas of Brazil indicate a decline in the consumption of basic traditional foods, such as rice and beans; notable increases (up to $400 \%$ ) in the consumption of processed food items, such as cookies and soft drinks; maintenance of the excessive consumption of sugar; and continuous increases in the content of total fat and saturated fat in the diet ${ }^{(23)}$

Analysis of Brazilian HBS has also been conducted in relation to the price of food groups. One of these studies, conducted in the city of São Paulo from 1990 to 1996, classified food groups into industrialized and nonprocessed foods and revealed that expenditure on the non-processed group decreased by $35 \%$ during the period, although these changes could not be fully explained by variations in product prices ${ }^{(24)}$. Therefore, differences in food expenses were not based solely on income. On the other hand, income appears to have an influence on fruit and vegetable purchases. A recent analysis based on the National HBS 2002-3 showed that a reduction in price would increase the purchase of these items, which are not frequently consumed ${ }^{(25)}$. In line with this result, a population-based study in the municipality of São Paulo, based on telephone interviews, indicated that consumption of foods indicative of an unhealthy diet such as sugars and fats was inversely associated with fruit and vegetable intake among subjects of both genders ${ }^{(26)}$.

It is not completely understood why and how sugar consumption is associated with obesity and a review on this subject did not show a direct association between obesity and sugar consumption ${ }^{(27)}$. Other studies suggest that the glycaemic index (GI), defined as the area under the glucose response curve after consumption of $50 \mathrm{~g}$ carbohydrate from a test food divided by the area under the curve after consumption of $50 \mathrm{~g}$ carbohydrate from a control food, is associated with an increase in insulin levels and C-peptide excretion ${ }^{(7,28,29)}$. Thus, the hyperinsulinaemia associated with high-GI diets might promote weight gain by preferentially directing nutrients away from oxidation in muscle and towards storage in $\mathrm{fat}^{(28)}$. It is also suggested that consumption of sugar-sweetened drinks could lead to obesity because of imprecise and incomplete compensation for energy consumed in liquid form ${ }^{(19)}$. A study among twelve obese male teenagers demonstrated that consumption of high-GI foods induces hormonal and metabolic changes possibly causing obesity ${ }^{(29)}$.

In parallel with the increase in sugar intake, the refining process has changed the composition and quality of carbohydrates. Processing grains into white flour increases the energy density by $10 \%$, reducing the content of fibre by $80 \%$ and also the protein content by almost $80 \%{ }^{(7)}$.

The mean relative contribution of vegetal oils to total energy observed in the present study was $12 \cdot 80 \%$, varying from $7 \cdot 86 \%$ to $17 \cdot 09 \%$. This group was not found to be correlated with obesity, although margarine showed a fair association among women. These results may suggest that other factors, rather than fat consumption, are responsible for body fatness. Another possibility is that fat consumption occurs mainly away from home. Adults who usually eat away from home have higher total energy and fat intakes, and lower fibre consumption ${ }^{(30)}$. A study of 
restaurant food and body fatness showed that frequency of consumption of restaurant food was positively associated with body fatness, independently of educational level, smoking status, alcohol intake and physical $\operatorname{activity}^{(22)}$.

The present study focused on the relationship between family food availability and the prevalence of obesity in twenty-six state capitals of Brazil. The major limitation of an ecological study is the difficulty in controlling for confounding factors ${ }^{(31,32)}$. We chose capitals instead of states or other units of analysis as a way to minimize errors in this inference, using data from homogeneous population groups ${ }^{(32)}$. The selected capitals have quite similar percentages of jobs requiring high energy expenditure, $\sim 3 \%{ }^{(33)}$, and also the proportion reporting regular physical activity during leisure time in each capital was $\sim 20 \%{ }^{(34)}$.

In conclusion, increasing intake of refined carbohydrates, mainly from soft drinks, may have a role in the prevalence of obesity in Brazil. The present survey corroborated the results of other studies and suggests that effecting changes in family purchase patterns may be a strategy to reduce obesity.

\section{Acknowledgements}

J.C.P.L. was funded by a Fellowship-Master degree grant from the Brazilian Coordinating Center for Training University Level Personnel (CAPES). No author had any conflict of interest relating to the study. J.C.P.L. was responsible for the statistical analysis and writing of the manuscript. R.S. participated in the study's conception, data interpretation and writing of the manuscript. A.J.L.C. participated in the study's conception, data interpretation and writing of the manuscript.

\section{References}

1. Stein CJ \& Colditz GA (2004) The epidemic of obesity. $J$ Clin Endocrinol Metab 89, 2522-2525.

2. Jeffery RW \& Utter J (2003) The changing environment and population obesity in the United States. Obes Res 11, Suppl. 1, 12S-22S.

3. Organização mundial de saúde (2004) Obesidade: prevenindo e controlando a epidemia global/Relatório da consultoria da OMS [A Favano, tradução; SS Maeda, revisão científica]. São Paulo: Roca.

4. Popkin BM (2001) The nutrition transition and obesity in the developing world. J Nutr 131, Suppl. 3, 871S-873S.

5. Instituto Brasileiro de Geografia e Estatística (2004) Pesquisa de Orçamentos Familiares 2002-2003: primeiros resultados. Brasil e grandes regiões. Rio de Janeiro: IBGE.

6. Instituto Brasileiro de Geografia e Estatística (2004) Pesquisa de Orçamentos Familiares 2002-2003: análise da disponibilidade domiciliar de alimentos e do estado nutricional no Brasil. Rio de Janeiro: IBGE.

7. Gross LS, Li L \& Ford ES (2004) Increased consumption of refined carbohydrates and the epidemic of type 2 diabetes in the United States: an ecologic assessment. Am J Clin Nutr 79, 774-779.

8. Bray GA \& Popkin BM (1998) Dietary fat intake does affect obesity! Am J Clin Nutr 68, 1157-1173.

9. Franco G (1992) Tabela de composição química dos alimentos, $9^{\underline{a}}$ ed. São Paulo: Atheneu.

10. Núcleo de Estudos e Pesquisas em Alimentação/Universidade Estadual de Campinas (2004) Tabela Brasileira de Composição de Alimentos [TACO]: versão 1. São Paulo: NEPA/Unicamp.

11. Souci SW, Fachmann W \& Draut H (1994) Food Composition and Nutrition Tables, 5th ed. Stuttgart: Medpharm Scientific.

12. Health and Consumer Protection Directorate-General (2005) The DAFNE Food Classification System. Operationalisation in 16 European Countries. Luxembourg: European Commission.

13. Sichieri R, Coitinho DC, Leão MM, Recine E \& Everhart JE (1994) High temporal, geographic, and income variation in body mass index among adults in Brazil. Am J Public Health 84, 793-798.

14. Sichieri R (1998) Epidemiologia da obesidade. Rio de Janeiro: UERJ.

15. Lin BH \& Frazao E (1997) Nutritional quality of foods at and away from home. Food Rev 2, 33-40.

16. Naska A, Vasdekis VGS \& Trichopoulou A (2001) A preliminary assessment of the use of household budget survey data for the prediction of individual food consumption. Public Heath Nutr 4, 1159-1165.

17. Neuhouser ML, Tinker L, Shaw PA et al. (2008) Use of recovery biomarkers to calibrate nutrient consumption self-reports in the Women's Health Initiative. Am J Epidemiol 167, 1247-1259.

18. World Health Organization/Food and Agriculture Organization of the United Nations (2003) Diet, Nutrition and the Prevention of Chronic Diseases. WHO Technical Report Series no. 916. Geneva: WHO.

19. Ludwig DS, Peterson KE \& Gortmaker SL (2001) Relation between consumption of sugar-sweetened drinks and childhood obesity: a prospective, observational analysis. Lancet 357, 505-508.

20. Harnack LJ, Stang J \& Story M (1999) Soft drink consumption among US children and adolescents: nutritional consequences. J Am Diet Assoc 99, 436-441.

21. Popkin BM \& Nielsen SJ (2003) The sweetening of the world's diet. Obes Res 11, 1325-1330.

22. McCrory MA, Fuss PJ, Saltzman E \& Roberts SB (2000) Dietary determinants of energy intake and weight regulation in healthy adults. J Nutr 130, 2S Suppl., 276S-279S.

23. Levy-Costa RB, Sichieri R, Pontes Ndos S \& Monteiro CA (2005) Household food availability in Brazil: distribution and trends (1974-2003). Rev Saude Publica 39, 530-540.

24. Barreto SA \& Cyrillo DC (2001) Analysis of household expenditures with food in the city of S. Paulo in the 1990's. Rev Saude Publica 35, 52-59.

25. Claro RM, Carmo HC, Machado FM \& Monteiro CA (2007) Income, food prices, and participation of fruit and vegetables in the diet. Rev Saude Publica 41, 557-564.

26. Figueiredo IC, Jaime PC \& Monteiro CA (2008) Factors associated with fruit and vegetable intake among adults of the city of São Paulo, Southeastern Brazil. Rev Saude Publica 42, 777-785.

27. Hill JO \& Prentice AM (2003) Sugar and body weight regulation. Am J Clin Nutr 62, 1 Suppl., 264S-274S.

28. Ludwig DS (2000) Dietary glycemic index and obesity. J Nutr 130, 2S Suppl., 280S-283S.

29. Ludwig DS, Majzoub JA, Al-Zahrani A, Dallal GE, Blanco I \& Roberts SB (1999) High glycemic index foods, overeating, and obesity. Pediatrics 103, E26-E31. 
30. McCrory MA, Fuss PJ, McCallum JE, Yao M, Vinken AG, Hays NP \& Roberts SB (1999) Dietary variety within food groups: association with energy intake and body fatness in men and women. Am J Clin Nutr 69, 440-447.

31. Medronho RA (2002) Estudos ecológicos. In Epidemiologia, $2^{\mathrm{a}}$ ed, pp. 191-198 [RA Medronho, DM Carvalho, KV Bloch, RR Lviz and GL Werneck, editors]. São Paulo: Atheneu.
32. Morgenstern H (1982) Uses of ecologic analysis in epidemiologic research. Am J Public Health 72, 1336-1344.

33. Gomes VB, Siqueira KS \& Sichieri R (2001) Atividade física em uma amostra probabilística da população do Município do Rio de Janeiro. Cad Saude Publica 17, 969-976.

34. Anjos LA (2000) Physical activity estimates from a household survey in Brazil. Med Sci Sports Exerc 32, 5 S Suppl., S188. 